\title{
Evaluation Effect of Silver Acetate on Performance and Clostridium Perfringens-Induced Necrotic Enteritis in Broiler Chickens
}

\author{
Akhil Alsadwi $\mathbf{M}^{*}$, Abdaljaleel $\mathrm{R}^{1}$, Leyva-Jimenez $\mathbf{H}^{1}$, Ibrahim $\mathbf{M}^{1}$, Gardner $\mathrm{K}^{1}$, Al-Ajeeli $\mathbf{M}^{1}$, Bailey $\mathrm{CA}^{1}$, Cannon \\ $\mathrm{CL}^{2}$, Byrd JA $\mathrm{A}^{3}$ and Caldwell $\mathrm{D}^{3}$ \\ ${ }^{1}$ Department of Poultry Science, Texas A\&M University, USA \\ ${ }^{2}$ Department of Microbial Pathogenesis and Immunology Texas A\&M Health Science Center, USA \\ ${ }^{3}$ USDA Southern Plains Agriculture Research Center, College Station, USA \\ Submission: December 20, 2018; Published: January 09, 2019 \\ "Corresponding author: Akhil M. Alsadwi, Department of Veterinary Public Health, Baghdad University, Baghdad, Iraq, USA
}

\begin{abstract}
The objective of this study was to evaluate the potential effect of silver acetate (AgAc) on broiler chicken performance and necrotic enteritis development. The in vivo efficacy of AgAc delivered either by adding into the feed (as a prophylactic model) or via drinking water (as treatment model) during necrotic enteritis challenge was evaluated in two experiments. In Experiment 1, Feed-added AgAc, 210 one-d-old broiler chickens (Cobb-500) were blocked in 7 dietary treatment groups ( 6 replicates $/ 5$ birds each) as follows: Positive control (no AgAc and no challenge, $\mathrm{n}=30$ ), negative control (no AgAc and challenged, $\mathrm{n}=30$ ), and 5 dietary AgAc treatments ( $\mathrm{n}=30 /$ treatment) fed 20, 40, 60, 80, 100mg/kg feed AgAc for 21-d rearing period and challenged.

Necrotic enteritis was experimentally induced using an oral administration of netB positive-Clostridium perfringens type A ( $3 \mathrm{ml}$ per bird, $107 \mathrm{CFU} / \mathrm{mL}$ ) on days 16 and 17. In Experiment 2, Water-added AgAc, the same protocol was followed except the birds (Ross-308) received the AgAc concentrations via drinking water for the last 4days of the 21-d rearing period. Body weight and feed intake were recorded by pen on days 10,16 and 21 in both experiments. All birds were necropsied on d-21 to measure intestinal lesions associated with necrotic enteritis, and intestinal contents (med-ileum) of 12 birds per treatment were collected for Clostridium perfringens enumeration. Whether AgAc was added into the feed (for $21 \mathrm{~d}$ ) or in the water (4d), there were no differences $(\mathrm{P}>0.05)$ seen in bird performance, Clostridium perfringens enumeration, and lesion score compared to the positive and negative controls. These results suggest limitation effect of silver acetate on performance and reduce Clostridium perfringen colonization in broiler chickens.
\end{abstract}

Keywords: Silver ion; Necrotic enteritis; Broiler; Clostridium perfringens; Antibiotic

\section{Introduction}

Necrotic enteritis (NE) in broiler chickens is a bacterial infection caused by the Gram-positive, spore forming; anaerobic Clostridium perfringens type A (CP) within 2-6weeks of age [1]. $\mathrm{CP}$ is frequently found in the intestinal tract of healthy poultry, usually at levels lower than 102-104 CFU/g of intestine content verses $107-109 \mathrm{CFU} / \mathrm{g}$ in diseased birds [2,3]. Both clinical and sub-clinical forms of NE are known to cause industry losses of approximately US $\$ 6$ billion annually [4]. One strategy followed by animal producers to reduce or control the enteric bacterial burden of $\mathrm{CP}$ and subsequently promotes the growth performance; diets have been fortified with antibiotics as a growth promotor (AGP) [5]. Banning the use of AGP in European Union and increased restrictions and discouraging the use of AGP in the United States has a major impact on gut health in intensively reared broiler chickens [6].

Silver has been used as an antimicrobial agent in a variety of ways to control infections since ancient times [7]. Usually, silver has been used as ionic form (salts), mainly nitrate, sulphate or chloride. The antimicrobial activity of silver ions is characterized by a high effectiveness, low toxicity to host cells, and rare development of resistance [8]. Formulations of silver nitrate have been therapeutically well-known since the 18th century [9]. However, many of these inorganic forms rapidly lose effectiveness since the silver cations are released rapidly at the infection site [10]. The extensive use of silver-based compounds attracted animal-antibiotic alternative researchers to evaluate silver in particulate form as a feed additive in animal production (poultry and swine) relying mainly on the broad antimicrobial activity of silver ion [11-15]. However, scarce literatures evaluated the potential effect of less adverse effect of silver salts on broiler performance, or potential in vivo efficacy through a course of a disease using chicken as a model animal.

Silver acetate (AgAc) under anaerobic conditions exhibited bacteriostatic effect against CP with minimal inhibitory concentration (MIC) being $8 \mu \mathrm{g} / \mathrm{mL}$ (Alsadwi et al., under peer review). In addition, subjecting Clostridium perfringens to $40 \mu \mathrm{g}$ / $\mathrm{mL}$ of AgAc down regulated the expression of virulence genes 


\section{Archives of Animal \& Poultry Sciences (AAPS)}

of Clostridium perfringens (plc and netB) by 47- and 36-fold respectively. In terms of its toxicity, previous work done in our laboratory on potential in vivo toxicity using a single oral gavage, showed doses 10 and $100 \mathrm{mg} / \mathrm{kg}$ BW with less adverse effect compared to $1000 \mathrm{mg} / \mathrm{kg} \mathrm{BW}$ (Alsadwi et al., under peer review). In poultry, maximum tolerable level (MTL) of silver determined by [16] NRC (1980) is $100 \mathrm{mg} / \mathrm{kg}$ feed. The objective of this study was to evaluate the potential effect of AgAc (Sigma-Aldrich, 99.9\% purity; molecular weight $166.8 \mathrm{~g} / \mathrm{mol}$ ) on broiler chicken performance, Clostridium perfringens colonization, and lesion score associated with NE.

\section{Materials and Methods}

All procedures in this experiment were approved by the Institutional Animal Care and Use Committee of Texas A\&M University (IACUC 2017-0072).

Table 1: Feed composition of basal broiler starter diet used in both experiments

\begin{tabular}{|c|c|}
\hline Ingredients & $\%$ \\
\hline Yellow corn, grain & 62 \\
\hline Soybean meal (crude protein, 48\%) & 32 \\
\hline Soybean oil & 2.2 \\
\hline Limestone & 1.4 \\
\hline Sodium chloride (salt) & 0.5 \\
\hline Monocalcium phosphate & 1.6 \\
\hline DL-methionine & 0.23 \\
\hline L-Lysine-HCl & 0.18 \\
\hline Vitamin premix* & 0.25 \\
\hline Mineral Premix** & 0.05 \\
\hline Calculated composition & \\
\hline ME (kcal/kg) & 3050 \\
\hline Crude protein & 22 \\
\hline Crude fat & 3.92 \\
\hline Calcium & 0.95 \\
\hline Available phosphorus & 0.45 \\
\hline Lysine & 1.18 \\
\hline Methionine & 0.53 \\
\hline
\end{tabular}

1. Provided the following per kg of diet: vitamin A, $11 \mathrm{IU}$; vitamin $\mathrm{D} 3,3,850 \mathrm{IU}$; vitamin $\mathrm{E}, 45.8 \mathrm{IU}$; menadione, $1.5 \mathrm{mg}$; $\mathrm{B} 12$, $0.017 \mathrm{mg}$; biotin, $0.55 \mathrm{mg}$; thiamine, $2.93 \mathrm{mg}$; riboflavin, $5.96 \mathrm{mg}$; pantothenic acid, $20.17 \mathrm{mg}$; B6, $7.15 \mathrm{mg}$; niacin, $45.8 \mathrm{mg}$; folic acid, $1.74 \mathrm{mg}$; choline, $130.3 \mathrm{mg}$.

2. Trace minerals premix added at this rate yields (mg/kg): zinc, 60.0; manganese, 60.0; iron, 60.0; copper,7.0; iodine,0.4.

In Experiment 2, (Water-added AgAc [W-AgAc]), a total of 210 one-d-old straight Ross-300 broiler chickens were purchased from a commercial hatchery and placed into two Petersime battery brooders ( 5 birds per pen) inside an environmentally controlled rearing room. The room was thermostatically controlled with a 24-hour lighting provided. Each brooder pen contained supplemental heat as required. Birds were fed the control basal diet as in Experiment 1 from the day of hatch until termination of the experiment (d-21). In both experiments, feed and water were provided ad libitum. Birds were monitored daily with regard to general flock condition, temperature, lighting, water, feed, and any unanticipated events for the rearing facility.

\section{Birds and Management}

Two experiments were conducted at the same time in 2 separated rearing rooms at the USDA-ARS facility (College Station, TX). In Experiment 1, (Feed-added AgAc [F-AgAc]), a total of 210 one-d-old straight run Cobb-500 broiler chickens was purchased from a commercial hatchery and placed in two stainless steel battery brooder units (Alternative Design Manufacturing and Supply Inc.) Five birds by pen (2sq. ft. per cage) were allocated inside environmentally controlled rearing rooms. The room was thermostatically controlled with a 24-hour lighting provided. Birds were fed a corn-soy broiler starter diet (Table 1) either as a control (unsupplemented) or supplemented with graded concentrations of AgAc from the day of hatch until termination of the experiment (d-21).

\section{Experimental Design}

The in vivo efficacy of AgAc delivered either by adding into the feed (as a prophylactic model) or via drinking water (as treatment model) during necrotic enteritis challenge was evaluated. Birds in F-AgAc group were blocked based on initial body weight in 7 dietary treatment groups (6 replicates/5 birds each) as follows: Positive Control (PC) (no AgAc and no challenge, $n=30$ ), Negative Control (NC) (no AgAc and challenged, $\mathrm{n}=30$ ), and 5 dietary AgAc treatments ( $\mathrm{n}=30 /$ treatment) fed $20,40,60,80,100 \mathrm{mg} / \mathrm{kg}$ feed AgAc for 21-d rearing period and challenged. These concentrations were chosen based on our in vivo toxicity preliminary study. 
For the W-AgAc group, the same protocol was followed except the birds (Ross-308) received AgAc concentrations via drinking water for the last 4 days of the 21-d rearing period. Treated groups received AgAc fresh daily or as needed using a jack-waterer. Water consumption for the last 4 consecutive days was recorded to calculate the amount of AgAc delivered. In both experiments, feed consumption and body weight (BW) per pen were recorded on d 10, 16 and 21 to calculate weight gain (WG) and feed to weight ratio (FCR). Mortality and body weight of dead birds was recorded daily and used to adjust FCR. On d-21, all birds were euthanized using $\mathrm{CO} 2$, and necropsied to measure intestinal lesions associated with NE, and intestinal content from 12 birds per treatment were collected for Clostridium perfringens enumeration.

\section{Clostridium Perfringens Challenge}

Birds from both trials were administered a commercial infectious bursal disease vaccine (IBD, Bursa-Vac, Merck Animal Health, Summit, NJ) at $10 \mathrm{X}$ the recommended dose via the ocular route on day 10 in order to help induce NE by acting as immunosuppressive [17]. Four field isolates of Clostridium perfringens type A from different geographical locations confirmed with NE infection ( 2 isolates from Texas and Virginia and 2 isolates from Georgia) were cultured separately on thioglycollate medium (Becton Dickinson) for $12 \mathrm{~h}$ then combined and provided to the appropriate treatment groups [17]. Chicks were challenged via oral gavage (3mL) with $107 \mathrm{CFU}$ of $\mathrm{CP} / \mathrm{mL}$ on days 16 and 17 .

\section{Clostridium perfringens Enumeration}

A section $(\sim 15 \mathrm{~cm})$ of the small intestine caudal to Meckel's diverticulum was removed and placed in $10 \mathrm{~mL}$ of anaerobic thioglycollate (Becton Dickinson). Then, the sample was stomached for $30 \mathrm{sec}$, and $0.5 \mathrm{~mL}$ of small intestine contents transferred into $4.5 \mathrm{~mL}$ of thioglycollate medium. Ten-fold serial dilutions were performed and plated on Shahidi Ferguson Perfringens (SFP) agar supplemented with 50\% egg yolk enrichment, Antimicrobic Vial K (12mg), and Antimicrobic Vial P (30,000U) (Becton Dickinson). After the sample was plated, 10 to $12 \mathrm{~mL}$ SFP agar base without egg yolk enrichment was overlaid and the plates incubated anaerobically for $24 \mathrm{~h}$ at $37^{\circ} \mathrm{C}$. Colonies exhibiting typical colony morphology were counted and recorded [18].

\section{Lesion Score Associated with NE}

To evaluate the development of intestinal gross lesions associated with NE, scoring was performed as described by [19].

Table 2: Performance (from d 1-10, 10-16, and 16-21), Clostridium perfringens enumeration, lesion score and pairwise correlations (between daily silver intake ( $\mathrm{mg} / \mathrm{kg} \mathrm{BW}$ ) and studied responses) of broiler chickens fed different concentration of silver acetate. 1

\begin{tabular}{|c|c|c|c|c|c|c|c|c|c|c|}
\hline \multicolumn{11}{|c|}{ AgAc mg/kg feed (average daily AgAc intake mg/kg BW) } \\
\hline Response variable ${ }^{2}$ & $\mathrm{PC}(0)^{3}$ & NC $(0)$ & $20(1.9)$ & $40(3.7)$ & $60(5.4)$ & $80(7.2)$ & $100(9.1)$ & \multirow[b]{2}{*}{ PSEM } & \multirow[b]{2}{*}{$\mathbf{r}^{(5)}$} & \multirow[b]{2}{*}{ P value $^{6}$} \\
\hline & \multicolumn{7}{|c|}{ d 1-10 } & & & \\
\hline BW (g/bird) & 244 & 253 & 262 & 255 & 259 & 251 & 244 & 6.5 & -0.33 & 0.07 \\
\hline WG (g/bird & 206 & 215 & 225 & 218 & 221 & 213 & 207 & 6.5 & -0.33 & 0.07 \\
\hline FCR (g feed:g weight) & 1.04 & 1.02 & 1.05 & 1.02 & 1.05 & 1.04 & 1.03 & 0.01 & -0.1 & 0.59 \\
\hline Mortality (\%) & 0 & 6.6 & 10 & 0 & 10 & 3.3 & 6.6 & 4 & -0.05 & 0.79 \\
\hline
\end{tabular}




\section{Archives of Animal \& Poultry Sciences (AAPS)}

\begin{tabular}{|c|c|c|c|c|c|c|c|c|c|c|}
\hline & \multicolumn{7}{|c|}{ d 10-16 IBD Immune challenge } & \multirow[b]{2}{*}{12.1} & \multirow[b]{2}{*}{-0.36} & \multirow[b]{2}{*}{0.05} \\
\hline BW (g/bird) & 530 & 547 & 562 & 550 & 553 & 538 & 528 & & & \\
\hline WG (g/bird & 286 & 295 & 300 & 295 & 294 & 286 & 284 & 7.8 & -0.3 & 0.1 \\
\hline FCR (g feed:g weight) & 1.19 & 1.19 & 1.21 & 1.2 & 1.21 & 1.2 & 1.2 & 0.01 & -0.01 & 0.96 \\
\hline \multirow[t]{2}{*}{ Mortality (\%) } & 0 & 4.2 & 5.5 & 3.3 & 0 & 0 & 3.3 & 3 & -0.08 & 0.67 \\
\hline & \multicolumn{7}{|c|}{ d $16-21 \mathrm{CP}$ challenge } & & & \\
\hline BW (g/bird) & 819 & 823 & 805 & 844 & 842 & 842 & 791 & 18.8 & -0.06 & 0.74 \\
\hline WG (g/bird) & 289 & 275 & 244 & 294 & 289 & 304 & 262 & 14.8 & 0.21 & 0.26 \\
\hline FCR (g feed:g weight) & 1.29 & 1.31 & 1.34 & 1.3 & 1.32 & 1.31 & 1.31 & 0.02 & -0.21 & 0.25 \\
\hline Mortality (\%) & 0 & 9.7 & 8.3 & 6.6 & 4.2 & 10 & 0 & 5 & -0.08 & 0.66 \\
\hline Bacterial enumeration $^{4}$ & $0.75^{c}$ & $3.0^{\mathrm{ab}}$ & $4.1^{\mathrm{a}}$ & $3.3^{\mathrm{ab}}$ & $2.8^{\mathrm{ab}}$ & $3.4^{\mathrm{ab}}$ & $3.3^{\mathrm{ab}}$ & 0.59 & -0.2 & 0.13 \\
\hline Lesion Score ${ }^{4}$ & 0.63 & 0.79 & 0.91 & 0.83 & 0.86 & 0.68 & 1.1 & 0.1 & 0.14 & 0.14 \\
\hline
\end{tabular}

a-c Means within a row lacking a common superscript differ significantly $(P<0.05)$

1. The average mean of 6 replicates with 5 chicks per replicate $(n=6)$

2. Body weight (BW), weight gain (WG), feed conversion ratio (FCR)

3. Average daily silver acetate intake based on feed consumption for $21 \mathrm{~d} /$ average $\mathrm{kg}$ body weight, adjusted to mortalities

4. Bacterial enumeration= the average log $10 \mathrm{CFU}$ Clostridium perfringens/gram med-ileum content recovered from average 2 birds/pen ( $\mathrm{n}=6$ ), Lesion score $=$ the average score for pen $(n=6)$

5. Pairwise correlation between average daily silver acetate intake ( $\mathrm{mg} / \mathrm{kg} \mathrm{BW})$ and studied responses.

6. P value of Pairwise correlation

$\mathrm{PC}=$ Positive control (No challenge and no AgAc), NC=Negative control (Challenge and no AgAc), and 6 dietary treatments fed 20, 40, 60, 80, $100 \mathrm{mg} / \mathrm{kg}$ feed $\mathrm{AgAc}$ for $21 \mathrm{~d}$ rearing period and challenged with Clostridium perfringens on days 16 and 17.

AgAc delivered for 4 days (18-21) in drinking water up to $100 \mathrm{mg} / \mathrm{L}$ water (20.9 mg AgAc/kg BW/day) did not affect (P > 0.05 ) the productive parameters BW, WG, FCR, and mortalities compared to control groups (Table 3). Results showed negligible positive correlations between daily silver intake and BW $(\mathrm{r}=$ $0.12 ; \mathrm{P}=0.51)$, WG ( $\mathrm{r}=0.14 ; \mathrm{P}=0.46)$, and negligible negative correlations to FCR $(r=-0.20 ; P=0.28)$, and mortalities $(r=-0.15$; $\mathrm{P}=0.41)$.

\section{Clostridium perfringens Enumeration and Lesion Score}

Following CP challenge at d 16 and 17, CP enumeration and lesion score were performed on $\mathrm{d} 21$. In both F-AgAc and W-AgAc groups, all challenged treatments showed higher $(\mathrm{P}<0.05) \mathrm{CP}$ enumeration than in unchallenged group, and mortalities were only observed among the challenged treatments, except for highest dietary AgAc concentration ( $100 \mathrm{mg} / \mathrm{kg}$ feed), which confirmed that the chickens were successfully colonized by the bacteria. However, BW, WG, and FCR were not affected $(\mathrm{P}>0.05)$. These results are in line with results found by [21] and Fasina et al. [22] who reported no effect of the CP challenge on BW, WG, and FCR, however, the challenge groups had 1.5-2-fold higher $\mathrm{CP}$ enumeration compared to control group. The Clostridium perfringens strains used herein were type A alpha $(\alpha)$ toxin positive which are associated with NE incidence [23,24]. Swaggerty et al. [25] used the same strains to generate $\mathrm{NE}$ experimentally, and the author discussed that the NE from this model could mimic the sub-clinical NE in field. In the current study, using the same strains, which were further screened for presence of netB gene, the model still mimic the field NE as observed with low average lesion scores. Therefore, we tested ranges of silver acetate concentrations chosen from our preliminary toxicity study to assess the less adverse effects doses on CP intestinal recovery and lesion score associated with NE.

Table 3: Performance (from d 16-21), Clostridium perfringens enumeration, lesion score and pairwise correlations (between daily silver intake (mg/ $\mathrm{kg} \mathrm{BW}$ ) and studied responses) of broiler chickens delivered different concentrations of silver acetate in DW.1

\begin{tabular}{|c|c|c|c|c|c|c|c|c|c|c|}
\hline \multicolumn{11}{|c|}{ AgAc mg/L Water (Average Daily AgAc intake mg/kg BW) } \\
\hline Response Variable ${ }^{2}$ & $\mathrm{PC}(0)^{3}$ & $\mathrm{NC}(0)$ & $20(4.8)$ & $40(9.2)$ & $60(13.8)$ & $80(18.0)$ & $100(20.9)$ & & & \\
\hline & \multicolumn{7}{|c|}{ d $16-21$} & PSEM & $r^{(5)}$ & P value ${ }^{6}$ \\
\hline BW (g) & 762 & 750 & 722 & 797 & 819 & 743 & 766 & 24 & 0.12 & 0.51 \\
\hline WG $(g)$ & 273 & 251 & 214 & 284 & 308 & 249 & 252 & 24 & 0.14 & 0.46 \\
\hline FCR (g feed: g weight) & 1.34 & 1.31 & 1.39 & 1.36 & 1.29 & 1.29 & 1.36 & 0.04 & -0.2 & 0.28 \\
\hline Mortality (\%) & 0 & 6.6 & 14.2 & 6.6 & 10 & 6.6 & 6.6 & 5 & -0.15 & 0.41 \\
\hline
\end{tabular}




\section{Archives of Animal \& Poultry Sciences (AAPS)}

\begin{tabular}{|c|c|c|c|c|c|c|c|c|c|c|}
\hline Bacterial Enumeration $^{4}$ & $0.61^{\mathrm{c}}$ & $3.4^{\mathrm{ab}}$ & $4.4^{\mathrm{a}}$ & $3.8^{\mathrm{ab}}$ & $3.3^{\mathrm{ab}}$ & $3.3^{\mathrm{ab}}$ & $3.2^{\mathrm{ab}}$ & 0.71 & -0.23 & 0.1 \\
\hline Lesion Score $^{4}$ & 0.3 & 0.4 & 0.24 & 0.49 & 0.18 & 0.15 & 0.39 & 0.09 & -0.04 & 0.65 \\
\hline
\end{tabular}

a-c Means within a row lacking a common superscript differ significantly $(P<0.05)$

1. The average mean of 6 replicates with 5 chicks per replicate $(n=6)$

2. Body weight (BW), weight gain (WG), feed conversion ratio (FCR)

3. Average daily silver acetate intake based on feed consumption for $21 \mathrm{~d} /$ average $\mathrm{kg}$ body weight, adjusted to mortalities

4. Bacterial enumeration= the average log10 CFU Clostridium perfringens/gram med-ileum content recovered from average 2 birds/pen $(n=6)$, Lesion score $=$ the average score for pen $(n=6)$

5. Pairwise correlation between average daily silver acetate intake ( $\mathrm{mg} / \mathrm{kg} \mathrm{BW}$ ) and studied responses.

6. $P$ value of Pairwise correlation

$\mathrm{PC}=\mathrm{Positive}$ control (No challenge and no $\mathrm{AgAc}$ ), $\mathrm{NC}=$ Negative control (Challenge and no $\mathrm{AgAc}$ ), and 6 treatment groups challenged with Clostridium perfringens and delivered 20, 40,60,80, $100 \mathrm{mg} / \mathrm{L}$ drinking water AgAc for the last 4 days of $21 \mathrm{~d}$ rearing period

Whether AgAc was added into the feed (for 21d) or in the water $(4 \mathrm{~d})$, there were no differences $(\mathrm{P}>0.05)$ seen in $\mathrm{CP}$ enumeration compared to challenged treatment (Tables 2 \& 3). Pairwise correlation results showed negligible negative correlation between daily silver intake $(\mathrm{mg} / \mathrm{kg} \mathrm{BW})$ and $\mathrm{CP}$ enumeration in both groups, F-AgAc $(r=-0.20 ; \mathrm{P}=0.13)$ and $\mathrm{W}-\mathrm{AgAc}(\mathrm{r}=-0.23 ; \mathrm{P}$ $=0.10)$. Similarly, whether AgAc was added into the feed or in the water, there were no differences seen in lesion scores compared to challenged treatment. In F-AgAc group, pairwise correlation results showed negligible positive correlation between daily silver intake (mg/kg BW) and lesion score $(r=0.14 ; \mathrm{P}=0.14)$, and negligible negative correlation $(\mathrm{r}=0.04 ; \mathrm{P}=0.65)$ in $\mathrm{W}-\mathrm{AgAc}$ group.

In F-AgAc group, lesion score of 2 (thin-walled, with focal necrosis, and grey in appearance with minor amounts of gas production), was observed in all dietary silver treatments with minor incidence percentages $(2 / 21(9.5 \%)$ in concentration 20 , $1 / 22(4.5 \%)$ in concentration $40,2 / 23(8.7 \%)$ in concentration $60,1 / 21(4.8 \%)$ in concentration $80,2 / 24(8.3 \%)$ in concentration 100. In addition, $2 / 24(8.3 \%)$ in concertation 100 showed lesion score of 3 . No such score lesion was observed in W-AgAc group. The intestinal lesions of the W-AgAc group had lower $(\mathrm{P}<0.05)$ lesion scores compared with the F-AgAc group at all concentrations tested including positive and negative controls (data not showed) Positive controls (unchallenged) in F-AgAc and W-AgAc showed lesion scoring of 0.64 , and 0.30 , respectively. However, these lesion scores in both positive controls were not different from their corresponding challenged groups $(\mathrm{P}>0.05)$.

\section{Discussion}

\section{Performance}

The very well toxicity profile for ionic silver has studied decades ago in broiler chickens in many studies in which ionic silver supplemented by either practical or purified diets and drinking water. These studies collectively showed that silver from silver acetate or silver nitrate is toxic at high concentrations (900 $\mathrm{mg} / \mathrm{kg}$ practical diet in poult and chickens [26,27], 1500mg/kg drinking water fed purified diet [28]). However, scarce literatures documented the potential effect of ionic silver on broiler chicken's performance, and on controlling an experimental infection using less adverse concentrations. This makes comparing current result relatively hard.

The performance results of current study collectively indicate whether AgAc included in the feed (from d 1 to 21) or drinking water (4d) at the concentrations evaluated in this experiment had no negative effect on broiler chicken performance. A practical diet containing graded concentrations $10,25,50$ and $100 \mathrm{mg} / \mathrm{kg}$ silver sulfate for 3 weeks did not affect growth performance and mortality of broiler chickens [29]. Early silver studies in growing turkeys showed that adding 100 ppm (about $110 \mathrm{mg} / \mathrm{kg} \mathrm{BW} /$ day) of silver nitrate or silver acetate (4 weeks) to the practical diet did not affect bird performance [26]. The results are also consistent with other studies using different forms of silver. Felehgari et al. [30] showed that silver nanoparticles fed to broiler chickens at 25 and $50 \mathrm{ppm}$ for $21 \mathrm{~d}$ did not affect the bird performance parameters BW, WG, and FCR. Similarly, Pineda et al. [14] reported that providing silver nanoparticles to broiler chickens at 10 and $20 \mathrm{mg} / \mathrm{kg}$ in drinking water from d 7 to 36 did not affect bird performance BW, FCR and mortalities.

It was reported the mechanism by which silver can induce adverse (toxic) effect on poultry (mainly reduce BW) is through interfering with metabolism and function of trace minerals such as copper $(\mathrm{Cu})$ and selenium (Se) [16]. It was reported that 50 and $100 \mathrm{mg} / \mathrm{kg}$ of silver increased mortalities and reduced growth rate of chicks fed for 3 weeks a copper purified diet, and supplementation 10 and $25 \mathrm{mg} / \mathrm{kg}$ copper prevented the adverse effects of silver [29]. The premix of our diet provided $7 \mathrm{mg} / \mathrm{kg}$ copper which could marginally prevent the potential adverse effect of silver as showed with low negative correlation between average daily silver intake and BW and WG. Following oral exposure to both ionic and nanoparticulate silver suspensions, silver has been reported to be deposited as particles in tissues such as the epidermis, the glomeruli and the intestines [31]. These particles, in the rat intestines, were found to contain sulphur and selenium in addition to silver [32]. This led to the conclusion that Se and the other mineral such as $\mathrm{Cu}$ are antagonistic to silver ion preventing the bioavailability. Similarly, the calculated Se in our corn-soy diet provided $0.15 \mathrm{mg} / \mathrm{kg}$ Se which could play a role 
to reduce toxic effects of silver ions by reducing their biological availability. In addition, it has been shown that the efficacy of silver can be affected by the interaction of the ions with chloride, which results in the formation silver chloride $(\mathrm{AgCl})$ precipitate [33]. It is possible readily released silver ions from AgAc interacted with biologically-relevant compounds (such as organic material or chloride) in the drinking water, preventing their bioavailability.

Beside no adverse effect, no positive effect of adding silver into the feed or water was noticed. The metabolic interactions of silver with different essential metals which eventually lead to toxic effect and diminish silver bioactivity is contradicted (at least for this form of silver) to the hypothesis says: as silver ion possesses antimicrobial activity, silver could potentially modify the microbiota profile of gastrointestinal tract [34], and subsequently could promote the bird performance resembling the antibiotic growth promoter action [11,13]. Based on this hypothesis, silver availability in the GIT is a key factor to achieve this goal. Sawosz et al. [11] reported no major effect of colloidal silver on bacterial population in the digestive tract of quails, however, only a significant increase in lactic acid bacteria was observed with $25 \mathrm{mg} / \mathrm{kg}$ in drinking water. No effect of silver in particulate form on microbial population including Clostridium perfringens when broiler chicken supplemented 10 and $20 \mathrm{mg} / \mathrm{kg}$ drinking water for 22days with no positive effect on bird performance BW and FCR [14].

Vadalasetty et al. [15] reported that the application of particulate silver via drinking water in the concentration of $50 \mathrm{mg} /$ $\mathrm{kg}$ had no antibacterial effect on different intestinal bacterial groups including Clostridium perfringens, but this concentration led to decrease the BW. Hadrup et al. [34] showed neither silver nanoparticle $(9 \mathrm{mg} / \mathrm{kg} \mathrm{BW} /$ day) nor silver acetate $(14 \mathrm{mg} / \mathrm{kg}$ BW/day) affected the balance between the two main phyla of gastrointestinal tract bacteria in GIT of rates, Firmicutes and Bacteriodetes. The author suggested that silver nanoparticles and silver acetate in the applied doses did not disturb the microbiological balance of the gastrointestinal environment at the phyla level.

\section{Clostridium Perfringens Enumeration and Lesion Score}

Controlling pathogen infections in the gastrointestinal tract of animals using silver-based compounds, in particular silver salt forms, are scarcely reported. Although, in vitro antibacterial efficacy of AgAc against Clostridium perfringens type A was a bacteriostatic effect with MIC being $8 \mu \mathrm{g} / \mathrm{mL}$, it seems that in vivo efficacy of AgAc, to reduce bacterial colonization in the intestine, was limited. Similar results found by Vadalasetty et al. [15] who reported that the application of particulate silver via drinking water in the concentration of $50 \mathrm{mg} / \mathrm{kg}$ had no antibacterial effect on different intestinal bacterial groups including Clostridium perfringens and had no effect on colonization of Campylobacter jejuni experimentally infected in broiler chickens although the in vitro results showed bactericidal at the same concentration used in vivo.
Regardless the lesion scores observed in the PC of both experiments, which could explain the ubiquitous of Clostridium perfringens in the environment, AgAc in both delivery methods did not decrease or increase the lesion scores compared to lesion scores of challenged groups. Although there were no significant differences in Clostridium perfringens enumeration in both delivery methods groups, the intestinal lesions of the W-AgAc group had lower $(\mathrm{P}<0.05)$ lesion scores compared with the F-AgAc group at all concentrations tested including positive and negative controls. The lesion score of 2 and 3 noticed in small number of birds in F-AgAc group increased the overall average of lesion score compared to W-AgAc. This could indicate (although low number of chickens showed these lesion) that silver could exert its toxicity when supplemented for prolong period at low levels which limiting the use of silver as an antibacterial agent in animal production [11]. However, as the positive and negative controls showed difference in lesion score, the difference seen in lesion score may be due to an effect of strain, rather than an effect of silver administration. It was reported different immunological pathways are involved in genetic determinants outside the chicken B complex which have a significant impact on birds being either resistant or susceptible to NE [35]. Therefore, it was strongly suggested that different broiler strains have been shown to have different resistance to pathogens such as Clostridium perfringens [25].

It was proposed that the understanding of the potential behaviors of silver ions (whether it dissociated from salts or particulate silver) is not comprehensive in terms of their chemical and biochemical behavior in a biological system [33]. The in vivo antimicrobial efficacy of silver ion seems to be hindered by its interactions which probably explain the clearer effect on metabolic processes. The results of current study suggest limitation effect of silver acetate on performance, reduce Clostridium perfringens colonization and lesion score in broiler chickens.

\section{References}

1. Cooper KK and JG Songer (2010) Virulence of Clostridium perfringens in an experimental model of poultry necrotic enteritis. Vet Microbiol 142(3): 323-328.

2. Barnes EM, Mead GC, Barnuml DA, and Harry EG (1972) The intestinal flora of the chicken in the period 2 to 6 weeks of age, with particular reference to the anaerobic bacteria. Br Poult Sci 13(3): 311-326.

3. Craven SE, Cox NA, Stern NJ, and JM Mauldin (2001) Prevalence of Clostridium perfringens in commercial broiler hatcheries. Avian Dis 45(4): 1050-1053.

4. Wade B and Keyburn A (2015) The true cost of necrotic enteritis World Poultry.

5. Yegani M and Korver DR (2008) Factors Affecting Intestinal Health in Poultry. Poult Sci 87(10): 2052-2063.

6. Castanon JIR (2007) History of the use of antibiotic as growth promoters in european poultry feeds. Poult Sci 86(11): 2466-2471.

7. Russell AD and Hugo WB, Ellis GP and Luscombe DK (1994) 7 Antimicrobial Activity and Action of Silver. Progress in Medicinal Chemistry 31: 351-370.

8. Silver S (2003) Bacterial silver resistance: molecular biology and uses and misuses of silver compounds. FEMS Microbiol Rev 27(2-3): 341353. 
9. Klasen $\mathrm{HJ}$ (2000) Historical review of the use of silver in the treatment of burns. I. Early uses. Burns 26(2): 117-130.

10. Napoli M, Saturnino C, Cianciulli EI, Varcamonti M, Zanfardino A, et al. (2013) Silver(I) N-heterocyclic carbene complexes: Synthesis, characterization and antibacterial activity. Organomet Chem 725(4653).

11. Sawosz E, Binek M, Grodzik M, Zielińska M, Sysa P, et al. (2007) Influence of hydrocolloidal silver nanoparticles on gastrointestinal microflora and morphology of enterocytes of quails. Arch Anim Nutr 61(6): 444-451.

12. Sawosz E, Grodzik M, Zielińska-Górska M, Niemiec T, Olszanska B, et al. (2009) Nanoparticles of silver do not affect growth, development and DNA oxidative damage in chicken embryos. Europ Poult Sci 73(3): 208-213.

13. Fondevila M, Herrer R, Casallas MC, Abecia L, and Ducha JJ (2009) Silver nanoparticles as a potential antimicrobial additive for weaned pigs. Animal Feed Science and Technology 150(3-4): 259-269.

14. Pineda L, Chwalibog A, Sawosz E, Lauridsen C, Engberg R et al. (2012) Effect of silver nanoparticles on growth performance, metabolism and microbial profile of broiler chickens. Arch Anim Nutr 66(5): 416-429.

15. Vadalasetty KP, Lauridsen C, Engberg RM, Vadalasetty R, Kutwin M, (2018) Influence of silver nanoparticles on growth and health of broiler chickens after infection with Campylobacter jejuni. BMC Vet Res 14(1): 1.

16. Council NR, (1980) Mineral Tolerance of Domestic Animals. Natl Acad Press, Washington DC, USA, pp. 577.

17. Mc Reynolds JL, Byrd JA, Anderson RC, Moore RW, Edrington TS, et al. (2004) Evaluation of immunosuppressants and dietary mechanisms in an experimental disease model for necrotic enteritis. Poult Sci 83(12) 1948-1952.

18. Mc Reynolds JL, Byrd JA, Genovese KJ, Poole TL, Duke SE, et al. (2007) Dietary Lactose and its Effect on the Disease Condition of Necrotic Enteritis. Poult Sci 86(8): 1656-1661.

19. Prescott JF, Sivendra R, and Barnum DA (1978) The use of bacitracin in the prevention and treatment of experimentally-induced necrotic enteritis in the chicken. Can Vet J 19(7): 181-3.

20. Hinkle DE, Wiersma W, and Jurs SG, (2003) Applied statistics for the behavioral sciences 5th ed. (Fifth edition ed). Mass: Houghton Mifflin, Boston, Massachusetts, USA.

21. Fasina YO and Lillehoj HS (2018) Characterization of intestinal immune response to Clostridium perfringens infection in broiler chickens. Poult Sci pp. 390.

22. Fasina YO, Newman MM, Stough JM, and Liles MR (2016) Effect of Clostridium perfringens infection and antibiotic administration on

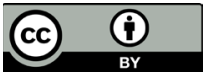

This work is licensed under Creative

Commons Attribution 4.0 License

DOI: 10.19080/AAPS.2019.01.555556 microbiota in the small intestine of broiler chickens. Poult Sci 95(2): 247-260.

23. Al-Sheikhly F and Al-Saieg A (1980) Role of Coccidia in the occurrence of necrotic enteritis of chickens. Avian Dis 24(2): 324-333.

24. Immerseel FV, Buck JD, Pasmans F, Huyghebaert G, Haesebrouck F, and Ducatelle R (2004) Clostridium perfringens in poultry: an emerging threat for animal and public health. Avian Pathol 33(6): 537-549.

25. Swaggerty CL, McReynolds JL, Byrd JA, Pevzner IY, Duke SE (2016) Selection for pro-inflammatory mediators produces chickens more resistant to Clostridium perfringens-induced necrotic enteritis. Poult Sci 95(2): 370-374.

26. Jensen LS, Peterson RP, and Falen L (1974) Inducement of Enlarged Hearts and Muscular Dystrophy in Turkey Poults with Dietary Silver. Poult Sci 53(1): 57-64.

27. Peterson RP and Jensen LS (1975) Interrelationship of Dietary Silver with Copper in the Chick1. Poult Sci 54(3): 771-775.

28. Bunyan J, Diplock AT, Cawthorne MA, and Green J (1968) Vitamin E and stress. 8. Nutritional effects of dietary stress with silver in vitamin E-deficient chicks and rats. Br J Nutr 22(2): 165-82.

29. Hill CH, Starcher B, and Matrone G (1964) Mercury and Silver Interrelationships with Copper. J Nut 83(2): 107-110.

30. Felehgari K, Ahmadi F, Rokhzadi A, Kurdestany AH, and Mohammadi M (2013) The effect of dietary silver nanoparticles and inorganic selenium supplementation on performance and digestive organs of broilers during starter period Bull. Env Pharmacol Life Sci 2(8): 104108.

31. Hadrup N and Lam HR (2014) Oral toxicity of silver ions, silver nanoparticles and colloidal silver - A review. Regul Toxicol Pharmacol 68(1): 1-7.

32. Loeschner K, Hadrup N, Qvortrup K, Larsen A, Gao X, et al. (2011) Distribution of silver in rats following 28 days of repeated oral exposure to silver nanoparticles or silver acetate. Part Fibre Toxicol 8(1): 18.

33. Behra R, Sigg L, Clift Martin JD, Herzog F, Minghetti M, et al. (2013) Bioavailability of silver nanoparticles and ions: from a chemical and biochemical perspective. J R Soc Interface 10(87): 20130396.

34. Hadrup N, Loeschner K, Bergström A, Wilcks A, Gao X, Vogel U, Frandsen HL, et al. (2012) Subacute oral toxicity investigation of nanoparticulate and ionic silver in rats. Arch Toxicol 86(4): 543-551.

35. Kim DK, Lillehoj HS, Jang SI, Lee SH, Hong YH, and Cheng HH (2014) Transcriptional profiles of host-pathogen responses to necrotic enteritis and differential regulation of immune genes in two inbreed chicken lines showing disparate disease susceptibility. PLOS ONE 9(12): e114960.

\section{Your next submission with Juniper Publishers will reach you the below assets}

- Quality Editorial service

- Swift Peer Review

- Reprints availability

- E-prints Service

- Manuscript Podcast for convenient understanding

- Global attainment for your research

- Manuscript accessibility in different formats

( Pdf, E-pub, Full Text, Audio)

- Unceasing customer service

Track the below URL for one-step submission https://juniperpublishers.com/online-submission.php 